\title{
Using Combined XRD-XRF Analysis to Identify Meteorite Ablation Debris
}

Saheeb Ahmed Kayani

Department of Mechanical Engineering,

College of Electrical and Mechanical Engineering, National University of Sciences and Technology, Peshawar Road, Rawalpindi, Pakistan 


\section{Combined XRD-XRF Analysis}

- XRF spectrometer is used to determine the individual component wavelengths of the fluorescent emissions produced when any material sample is exposed to X-rays.

- X-ray diffraction (XRD) is the technique of choice these days for determination of mineralogical make up of a variety of materials especially geological samples.

- The complimentary nature of XRD and XRF methods makes them invaluable for quantitative phase and elemental composition analysis. 


\section{Background Information}

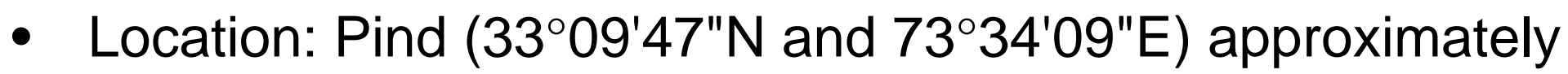

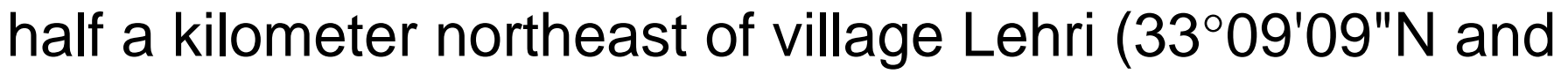

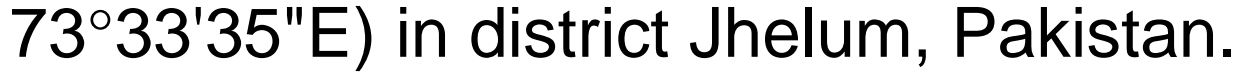

- For analysis purposes, representative samples were collected from different sites on the location using magnetic prospecting.

- These sites lie within a narrow patch of land approximately 100 $\mathrm{m}$ across and $250 \mathrm{~m}$ in length, extending north to south on both sides of the road that leads from village Lehri to a nearby village Rawatra, further up in the northeast direction. 


\section{Sample Appearance and Properties}

- Strongly magnetic

- Fairly distinguishable from rest of the soil

- Rough and pitted surfaces

- Depressions and shrinkage cracks

- Black in color with metallic luster

- Variable thickness $(0.5$ to $3 \mathrm{~cm})$

- Few are covered with a dull bronze colored layer (indicative of rusting attributable to weathering effects) 


\section{||||||||||||||||||||||||||||||||||||||||||||||||||||||||||}

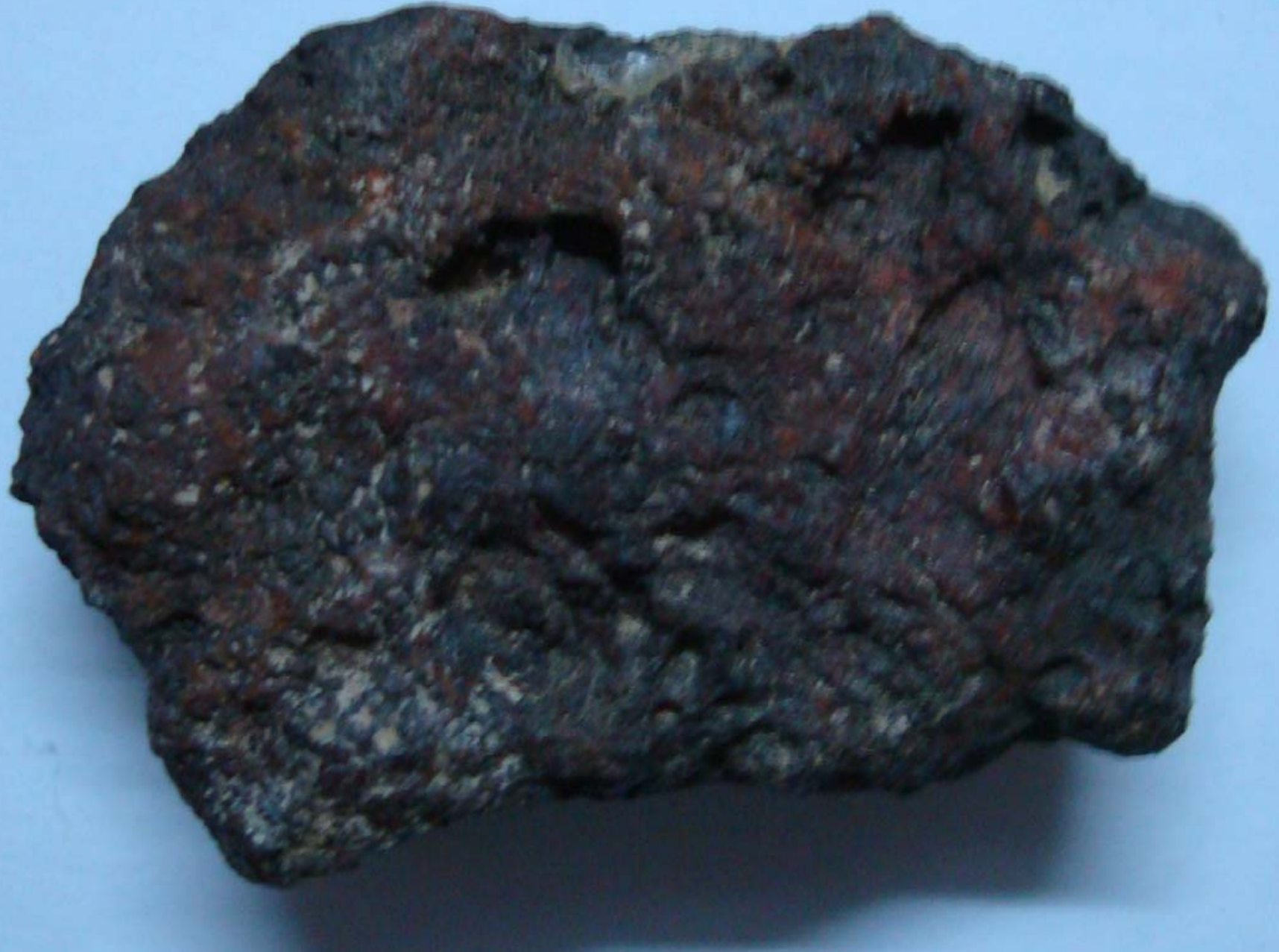

Sample 1: Tested at Geoscience Advance Research Laboratories, Islamabad using XRD and WD-XRF Analysis 


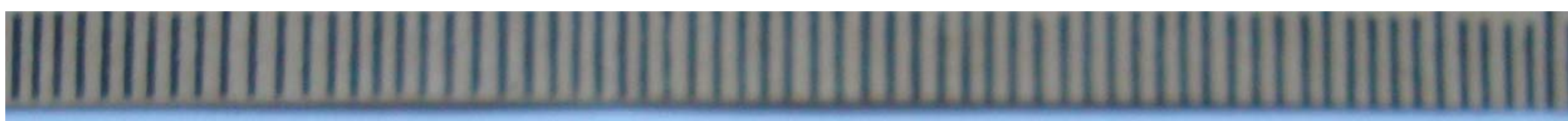

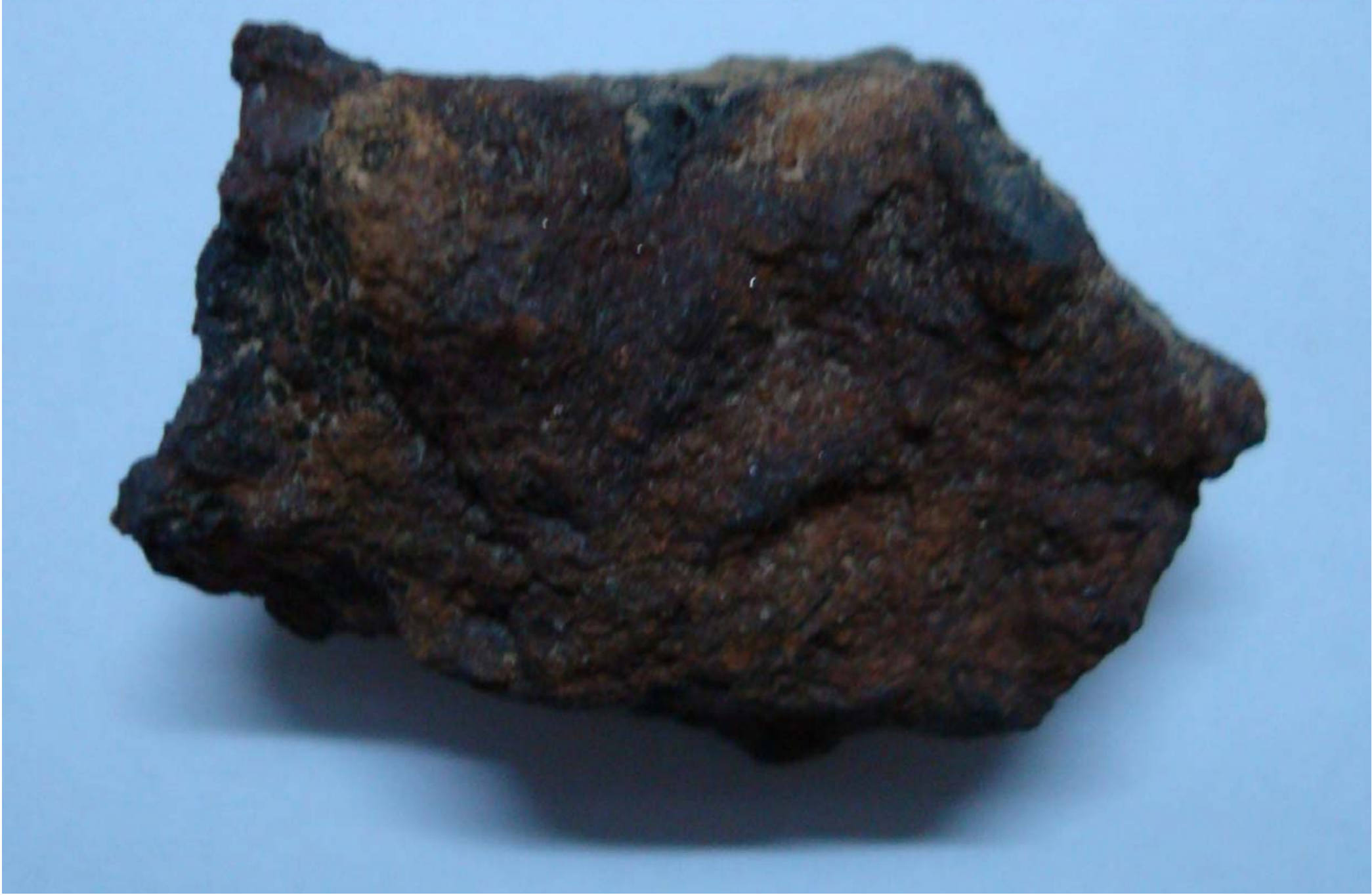

Sample 2: Tested at National Physical and Standards Laboratory, Islamabad using Standard Chemical Analysis 


\section{Likely Origins}

- Taking into account the physical characteristics, appearance, weight to size ratio and the very way in which this suspected stone variety is scattered over a limited area, three origins may be considered:

1. Volcanic (volcanic rock)

2. Industrial (waste/by product of some industrial process)

3. Extraterrestrial (meteorite ablation debris) 


\section{Test Results}

- The XRD analysis detected wüstite $\left(\mathrm{Fe}_{1-\mathrm{x}} \mathrm{O}\right)$ and magnetite $\left(\mathrm{Fe}_{3} \mathrm{O}_{4}\right)$ as predominant mineralogical phases in the outer crust of the tested sample stone.

- Elemental composition determined through XRF spectrometry analysis is included in the next slide.

- Presence of metallic phase in the interior structure of a polished surface of the tested sample stone is illustrated using photomicrographs taken with reflected light at $20 \times$ and $100 \times$ magnification. 


\begin{tabular}{|c|c|}
\hline Element & Composition (wt\%) \\
\hline $\mathrm{Si}$ & 3.93 \\
\hline $\mathrm{Ti}$ & 0.508 \\
\hline $\mathrm{Al}$ & 0.95 \\
\hline $\mathrm{Fe}$ & 56.28 \\
\hline $\mathrm{Mn}$ & 0.066 \\
\hline $\mathrm{Mg}$ & 0.342 \\
\hline $\mathrm{Ca}$ & 2.69 \\
\hline $\mathrm{Na}$ & 0.114 \\
\hline K & 0.146 \\
\hline$P$ & 0.228 \\
\hline V & 0.07 \\
\hline $\mathrm{Cr}$ & 0.324 \\
\hline $\mathrm{Ni}$ & 0.00786 \\
\hline $\mathrm{Sr}$ & 0.0093 \\
\hline $\mathrm{Ba}$ & 0.367 \\
\hline W & 0.024 \\
\hline $\mathrm{Cl}$ & 0.046 \\
\hline $\mathrm{Cu}$ & 0.0015 \\
\hline
\end{tabular}

Elemental Composition (wt\%) of the Sample Stone Determined through WD-XRF Spectrometry Analysis. 


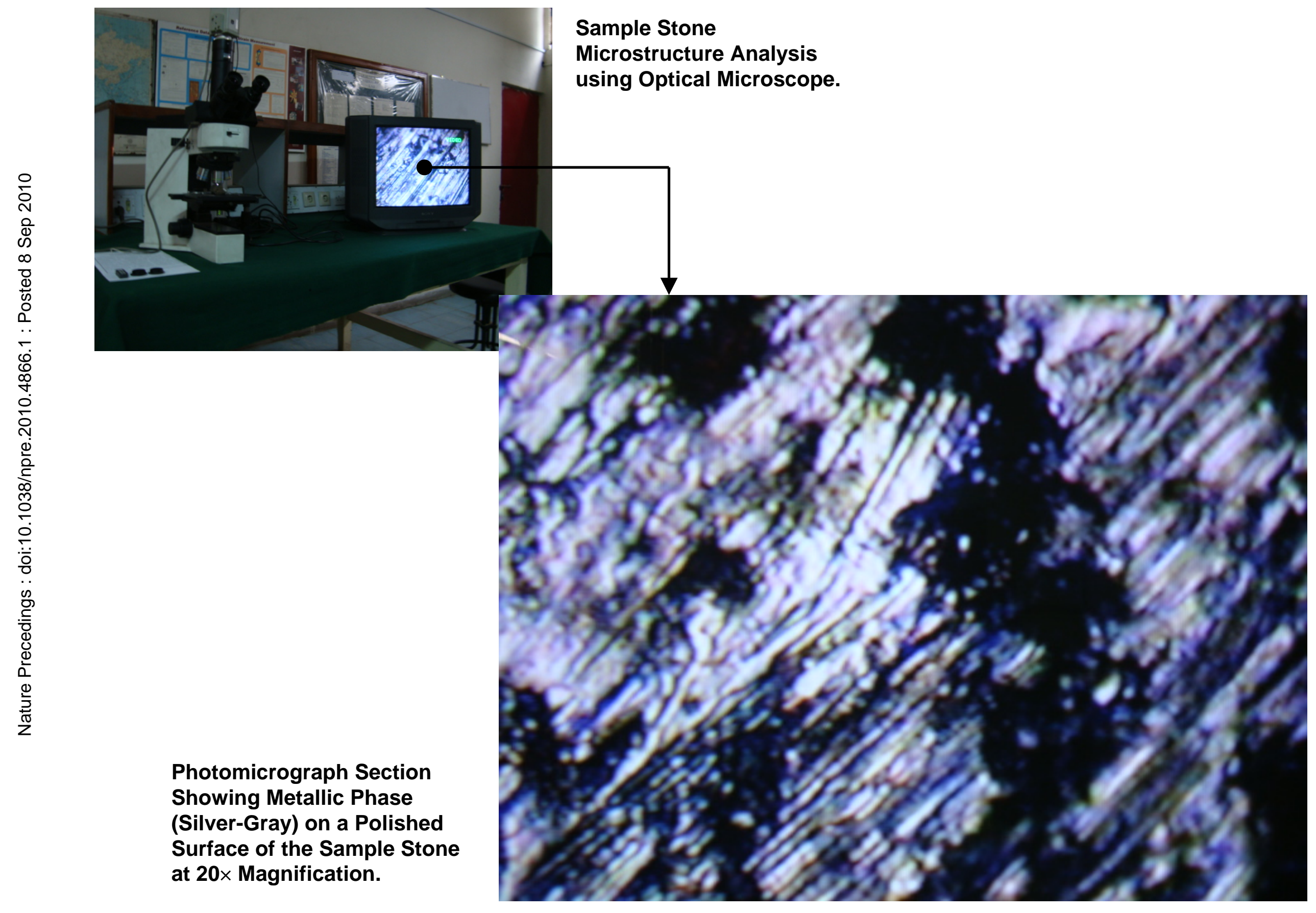


Metallic phase (white) observed at $100 \times$ magnification on a polished surface of the tested sample stone. Note almost round in shape single grain of metal phase with relatively well-defined boundary in the center of the photomicrograph section.

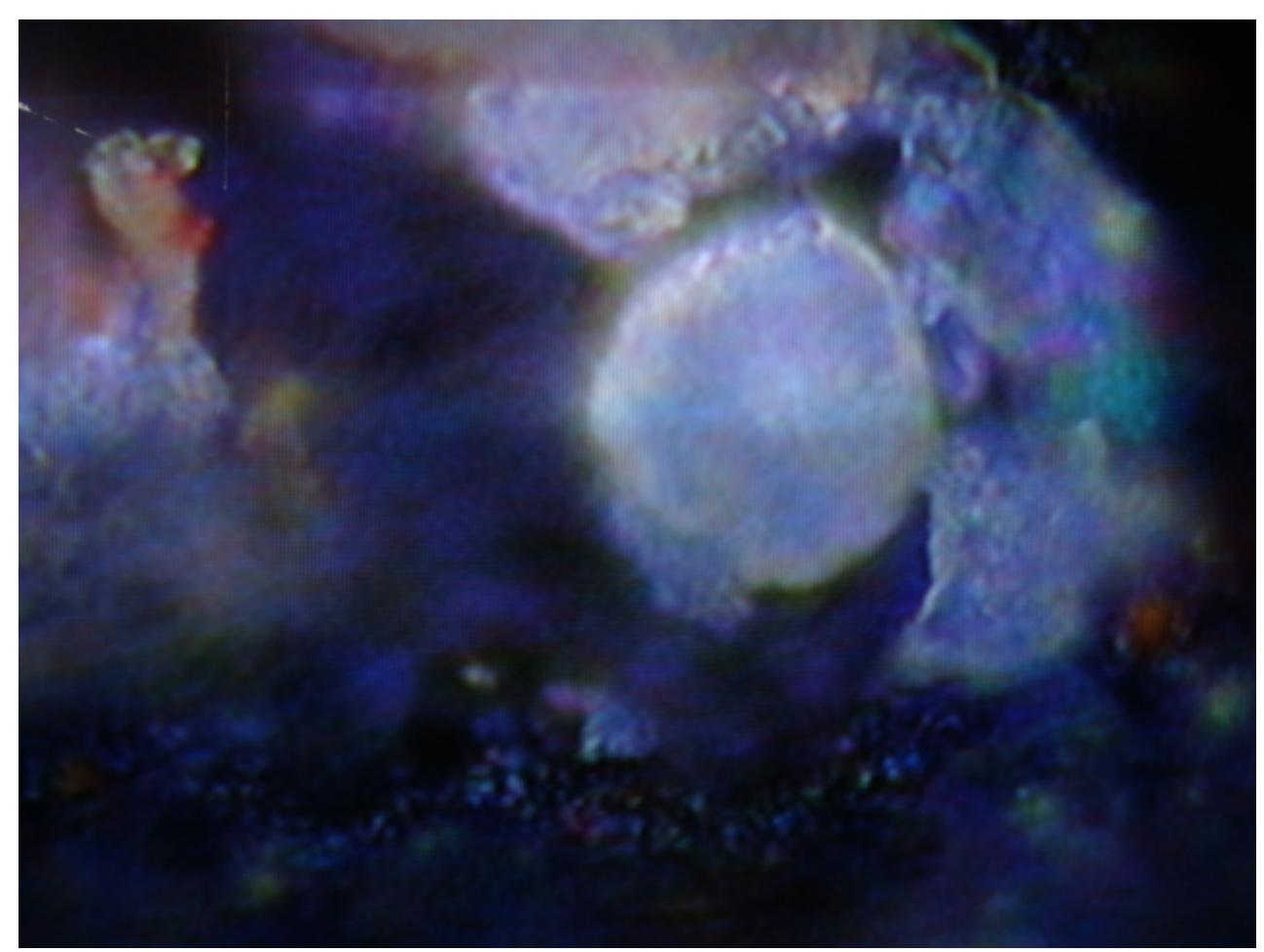




\section{Analysis}

\section{Volcanic}

(No)

- Presence of wüstite (shows existence of a highly reducing environment where as magmas offer high oxygen fugacities or increased possibility of oxidation than reduction).

- Volcanic magnetite contains $\mathrm{TiO}_{2}$ in the range of 4-30 wt $\%$ whereas in this case there is a very low abundance of $\mathrm{TiO}_{2}$ (0.848 wt\%) detected.
Industrial

(No)

- No industry associated setups in recent times or in past years have existed in or around the site.

\section{Meteorite Debris}

(Yes)

- Increased relative abundance of $\mathrm{Fe}$.

- Low abundance of cosmically abundant elements ( $\mathrm{Mn}, \mathrm{Cr}$, Ti etc.).

- Presence of wüstite (a rare Fe mineralogical phase mostly observed with meteorites undergoing ablation effects while passing through earth's atmosphere).

- Low Ni Content 


\section{Meteorite Type: Initial Hypothesis}

- Based on available physical, chemical and mineralogical data, the meteorite is classified as a chondrite. (Further testing through combustion analysis will be carried out to determine total carbon content, which in turn will be used to fix nature and origins of the meteorite debris.) 


\section{Meteorite Age: A Comment}

- Carbon dating can be used to ascertain the point in time when the meteorite entered earth's atmosphere and crashed on the site identified.

- Radiometric analysis can only be used to determine time periods in tens of thousands or in certain cases hundreds of thousands of years. i.e. Carbon dating $\sim 60,000$ years.

- As meteorites are the oldest specimens of matter in space, they tend to be as old as earth itself ( $\sim 4.55$ billion years) and were created as an outcome of very first geological processes in the primitive, slowly evolving solar system. 
Thank You 